\title{
Funding Research for Neglected Infectious Diseases: An Investment in the Future
}

\author{
Megan K. Meier
}

\author{
${ }^{1}$ Department of Biology, Colorado State University, Fort Collins, CO
}

\begin{abstract}
Neglected infectious diseases do not affect the majority of United States citizens. However, many of these diseases are rampant throughout developing countries. In 2002 these diseases were responsible for more than $50 \%$ of lives lost in African countries, but only 3\% of lives lost in developed countries, such as the United States (1). Any infectious disease can be considered "neglected" when there is insufficient therapeutic intervention available for the clinical management of that disease (2). Some common examples of neglected diseases that are prevalent in developing countries are malaria and tuberculosis. Developing countries do not have adequate funds to research possible therapeutics to cure the individuals with these diseases. The shortage of proper medications has prompted the United States to consider using tax dollars to begin research on these neglected diseases. This thought has sparked much debate as to if the United States should be investing additional money into problems that do not currently nor directly impact the homeland. While some view the investment as costly and not worth the United States' time, others view it as a worthy investment that could save present and future lives. It is the opinion of this author that tax dollars should be used to research and develop solutions for neglected diseases. The research is humanitarian, and the United States possesses the knowledge about neglected diseases, will benefit from economic gains, and can defend U.S. citizens against future outbreaks.
\end{abstract}

\begin{abstract}
Discussion
Using American tax dollars to fund the development of therapeutics for neglected diseases will save lives and the future of society. Many deaths are associated with neglected diseases each year, but research to find a cure is still not a priority. Even though these diseases account for $90 \%$ of the global disease burden only $10 \%$ of global investment in health research is put towards developing cures (3). Every year ten million children die in low-income countries due to the contraction of neglected diseases (3). Children are the future of the world. One day they will be expected to contribute to society; if many deaths are occurring, society will lose its future. With neglected disease therapeutics, disease can be cured and future lives can be saved. Although these countries have planned on developing therapeutics for neglected diseases, these countries do not have the technical or financial resources to complete the research (4). The United States could save people on a global scale and protect society's future if it decides to intervene and begin research.
\end{abstract}

In addition, it is irrational to waste knowledge. The United States has a plethora of neglected disease information. This knowledge should not be wasted, but instead used to perform research to find a cure. More is known on the biology on trypanosomes, the vectors of African sleeping sickness, than any other parasite. However, little research has been conducted, to date (5). Very little investment is put towards neglected disease research even though the United States has the resources. Only $\$ 42.00$ per fatal case of malaria is invested, which is eighty times lower than HIV and AIDS research and twenty times lower than asthma (5). With the knowledge and resources available, the United States should use these to develop therapeutics that could make a global impact.

By investing in research, both the United States and developing countries will benefit economically. The potential therapeutics will create healthier populations, which are more productive. During the last century, half of the United States' economic growth was attributed to health improvements (3). This economic growth is attributed to an increase in GDP per capita (3). Additionally, a healthier population tends to live longer. With an increased life expectancy, individuals can contribute more to the growth of the economy. Between 1970 and 2000, an additional \$3.2 trillion dollars were contributed to the United States' economy (3). Therapeutics would not only support a healthier United States population, but also increase developing countries' healthy populations. If developing countries had healthier populations, more people would work and contribute

This article is published under the terms of the Creative Commons Attribution License 4.0

Author(s) retain the copyright of this article. Publication rights with Alkhaer Publications.

Published at: http://www.ijsciences.com/pub/issue/2016-07/

DOI: 10.18483/ijSci.1074; Online ISSN: 2305-3925; Print ISSN: 2410-4477 
to the growth of the economy. Poverty rates would decrease significantly and GDP would increase. Both factors will positively impact any economy.

Investing in neglected disease therapeutic research will protect the United States in the future. A common healthcare goal is to be preventative. By maintaining a healthy population, the United States prevents any future diseases, which translates to lower future healthcare costs. If an outbreak ever occurred and a neglected disease were brought to the United States, the healthcare system could use the therapeutic to cure United States citizens. This would also save the United States money in the future because it would not have to rapidly perform research to create a treatment for the disease. Martin, Grant, and D'Angostino in the scientific journal, Global Health Funding and Economic Development, assert "proactive healthcare leads to a decrease in many of the additive healthcare costs associated with lack of care" (3). Moreover, tax dollars are used for defense. By investing in neglected disease research, the United States will also be investing in bio-warfare defense. With the increasing threat of bio-warfare, the United States will protect the homeland by having therapeutics ready to defend against any terror attacks that involved such technologies. The investment in research will prevent future outbreaks, save money, and protect the homeland.

While the therapeutics research can save lives and benefit countries economically, the use of United States' tax dollars towards the research meets much opposition. The United States has been known to step in when the world is experiencing a problem. The opposition believes that if the United States were to start developing drugs for diseases that are not common in the United States, many developing countries would become dependent on the United States to address future problems. Additionally, if the United States were able to create a medication after performing the research, then the United States would monopolize the market for that particular medication. By monopolizing the market of a medication, the United States could charge any monetary amount (6). Since research and development of therapeutics is extremely expensive, the United States would charge more than developing countries could afford. For instance, in the 1980s a pharmaceutical company held a monopoly on the recombinant Hepatitis B vaccine. The company was able to charge $\$ 23$ a dose and families in India affected by Hepatitis B could not afford the vaccine (6). Without access to medications, developing countries will not cure the neglected diseases. Developing nations cannot bear the costs associated with the research and development of therapeutics. Furthermore, some opposition claims that the United States will not benefit economically. The average out of pocket costs for a new therapeutic is $\$ 403$ million (1). During the research process for the neglected disease therapeutics, the United States government may need to contract with pharmaceutical manufacturers. Any research and development for the therapeutics will not give pharmaceutical manufacturers positive returns; therefore, many manufacturers will not be interested in contracting with the United States (1). Pharmaceutical manufacturers view the neglected disease therapeutic market as weak because the potential buyers, developing countries, do not have enough purchasing power (5). Even if the United States could convince these manufacturers to be involved, the United States will still have to pay for the drug review and orphan drug status (1). The trend of pharmaceutical companies not supporting neglected disease research can be traced back to the first half of the 2000s; five of the twelve top multinational companies were not conducting research on neglected diseases at this time (7). According to Daniel Vasella, the CEO of Novartis, one "can't expect for-profit organizations to" perform research that does not result in financial compensation (7). A 1991 study performed by Joseph DiMasi and his associates revealed that the sum of preclinical and clinical costs of drug development was \$231 million (8). Accounting for inflation over the past twenty-five years, the cost is even greater today. According to FDA standards, these neglected disease therapeutics would be considered priority drugs, which are more costly (8). With pharmaceutical manufacturers not willing to contribute towards the tremendous research costs, the United States would not experience any economic gains if investment were made towards neglected disease therapeutics.

Furthermore, developing countries do not regulate or distribute therapeutics properly. Policies regarding disease, medication, and healthcare are worse now because of an increase in disease and fewer qualified clinical pharmacists in developing countries (9). Educated healthcare professionals and healthcare organizations are critical for distributing proper treatment and medications. Only $9.6 \%$ of African countries have a pharmacology society (9). The Philippines, India, and Thailand are the only developing nations that recognize clinical pharmacy as a specialty (9). Developing countries also have lower medication diffusion speeds compared to developed countries. Urban areas only account for a small portion of these nations; poor communication between rural and urban areas results in slower diffusion speeds (10). With a lack of knowledge and poor distribution methods, developing countries would struggle using the therapeutics created by research.

In further opposition other countries are capable of 
performing research for these therapeutics. China, India, Brazil, and South Africa started biopharmaceutical improvements without the United States' assistance. In 1993 an Indian biotechnology company, Shantha Biotechnics, developed a process to develop Hepatitis B vaccine that reduced the price to one dollar per dose (6). While it may be surprising, developing countries have seen a growth in pharmaceutical industries. India's annual growth rate is $42 \%$, while the United States is a mere $2.6 \%$ (4). Additionally, India's Compound Annual Growth Rate (CAGR) for its pharmaceutical market is $16.6 \%$ compared to the United States' $2.9 \%$ (4). Since other countries are capable of researching and developing therapeutics, the United States should not take all the responsibility.

\section{Conclusions}

The global epidemic of infectious diseases cannot be refuted; however, a decision must be made as to if the United States wants to intervene by investing tax dollars to perform research for neglected disease therapeutics. The investment is extremely costly and the price for therapeutics could be too high for developing nations to afford. Additionally, developing countries would not know how to regulate or distribute the medications properly for them to efficiently cure the diseases. However, the benefits of the investment outweigh the costs. The United States will save many lives and put available scientific knowledge to good use. Investing in the research promotes the United States' economy as well as developing countries' economy. Furthermore, the United States could treat the research as biodefense; therefore, it will protect the homeland from future outbreaks. While the investment may be costly and seem unnecessary right now, neglected disease therapeutics research will benefit the United States in the future.

\section{Conflict of Interest}

The author declares no conflict of interest.

\section{References}

1) Ridley, D, Grabowski, H, Moe, J. Developing drugs for developing countries. Health Affairs. March 2006; 25:2.

2) Yamey, G. The world's most neglected diseases. British Medical Journal. July 2002; 325: 177-8.

3) Martin G, Grant A, D'Angostino M. Global health funding and economic development. Globalization and Health 2012; 8:8.

4) Rezaie, R, McGahan, A, Frew, S, Daar, A, Singer, P. Emergence of biopharmaceutical innovators in China, India, Brazil, and South Africa as global competitors and collaborators. Health Research Policy and Systems. 2012; 10:18.

5) Trouiller, P, Olliaro, P, Torreele, E, Orbinski, J, Laing, R, Ford, N. Drug development for neglected diseases: a deficient market and a public-health policy failure. The Lancet. June 2002; 359:9324.

6) Chakma J, Masum H, Perampaladas K, Heys J, Singer P Indian vaccine innovation: the case of Shantha Biotechnics. Globalization and Health. 2011; 7:9.

7) Lexchin, J. Canada and access to medicines in developing countries: intellectual property rights first. Globalization and Health. June 2013; 9:42.

8) DiMasi, J, Hansen, R, Grabowski, H. The price of innovation: new estimate of drug development costs. Journal of Health Economics. March 2003; 22:2.

9) Walubo, Andrew. The current status and trend of clinical pharmacology in developing countries. BMC Pharmacology and Toxicology. 28 September 2013; 14:49.

10) Desiraju, R, Nair, H, Chintagunta, P. Diffusion of new pharmaceutical drugs in developing and developed nations. International Journal of Global Marketing. December 2004; 21:4. 